Case Report

\title{
An unusual presentation of acute gastric volvulus in the elderly patient: a case report and literature review
}

\section{Aditya Prasad Padhy*, Inturi Pranay, Sarvesh Biradar}

Department of General Surgery, KIMS, Bhubaneswar, Odisha, India

Received: 13 June 2020

Accepted: 13 July 2020

\section{*Correspondence:}

Dr. Aditya Prasad Padhy,

E-mail: docadityapadhy@gmail.com

Copyright: (C) the author(s), publisher and licensee Medip Academy. This is an open-access article distributed under the terms of the Creative Commons Attribution Non-Commercial License, which permits unrestricted non-commercial use, distribution, and reproduction in any medium, provided the original work is properly cited.

\begin{abstract}
Gastric volvulus is nothing but the torsion of stomach in thoracic cavity by more than $180^{0}$ along its transverse or longitudinal axis. A very rare case occurring both in male and female. The term first described by Berti after doing an autopsy of a female, in 1886. We found a case of 65 years old male with history of dyspepsia since, 1 year with history of vomiting and pain abdomen since, 1 day. On evaluation, clinically gurgling sound heard on left side chest and with investigations like USG and CT whole abdomen, we came to know about mesentrico axial volvulus which is more common in children. Acute gastric volvulus cases have high mortality rate also requires emergency surgery. Gastric volvulus is very rare with variable and non-specific clinical presentations, hence high level of suspicion for radiologic diagnosis may require. Acute gastric volvulus is a potentially life-threatening occurrence with a good outcome when treated in a timely fashion. Chronic volvulus may be more difficult to recognize. Timely diagnosis with proper treatment can potentially decreases morbidity and mortality of the patient.
\end{abstract}

Keywords: Unusual presentation, Gastric volvulus, Elderly patient, Borchardt's triad, Gastric ischemia

\section{INTRODUCTION}

Abnormal rotation of the stomach by more than $180^{\circ}$, is a very rare clinical entity is difficult to diagnose and can be fatal in the acute scenario. Borchardt's triad of severe epigastric pain, retching and inability to pass a nasogastric tube is present $70 \%$ cases and is believed to be diagnostic for acute gastric volvulus. ${ }^{1}$

Complications like gangrene, perforation, gastric ischemia, pancreatic necrosis, omental avulsion and even splenic rupture. $^{2}$

The rarity of the disease accounts for the associated high mortality (30-50\%) and hence requires high index of clinical suspicion. ${ }^{3}$ A prompt and correct diagnosis followed by immediate surgery remains the key factor in reducing the morbidity and mortality.

\section{CASE REPORT}

A 65 years old male presented with c/c of dyspepsia, on aantacids for 7-8 years, with history of pain abdomen and vomiting since, 1 day. No known co-morbidities. Operated for bilateral inguinal hernia 10 years back. On examination: vitals stable, abdominal examination scar marks of previous hernia surgery present in groin region both sides, diffuse tenderness present over the whole abdomen more in epigastrium and left hypochondrium, bowel sound exaggerated. Chest examination percussion note dull in left infra mammary region, gurgling sound present in left infra mammary region. Chest X-ray revealed retro-cardiac air filled gastric and colonic shadow (Figure 1). USG abdomen mild left side pleural effusion. NCCT abdomen mesentro-axial gastric volvulus with elevated left dome of diaphragm and mediastinum shifted to right (Figure 2 and 3). 
Pre-operative diagnosis mesentro-axial gastric volvulus with diaphragmatic hernia.

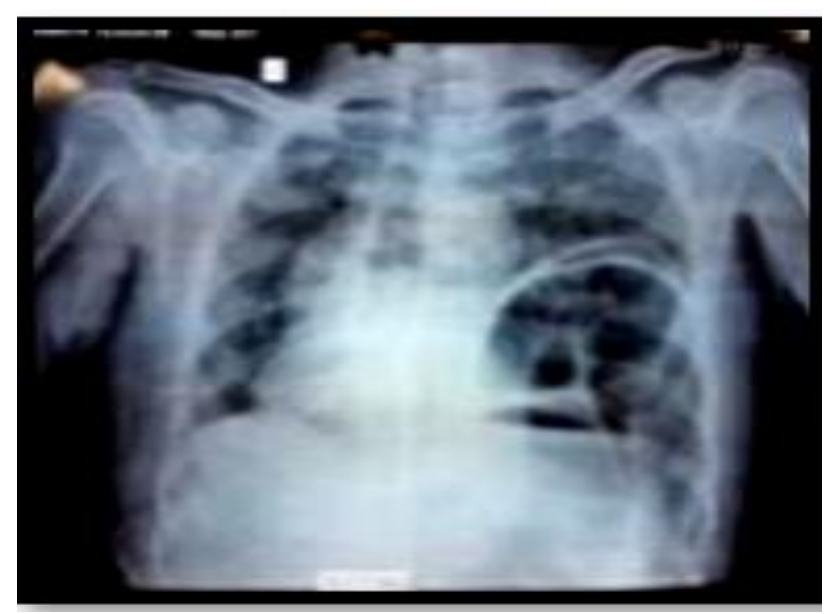

Figure 1: Showing pre-operative chest X-ray PA view.

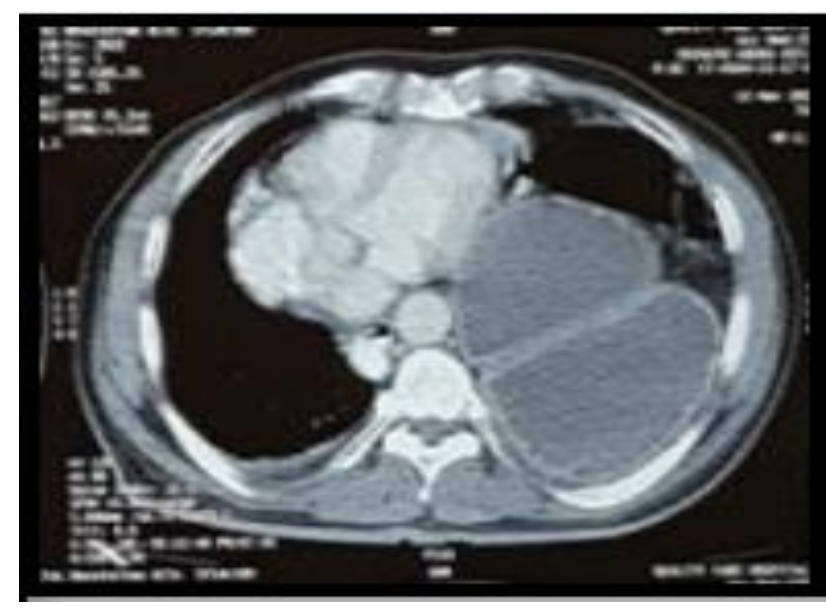

Figure 2: Showing transverse section of NCCT abdomen.

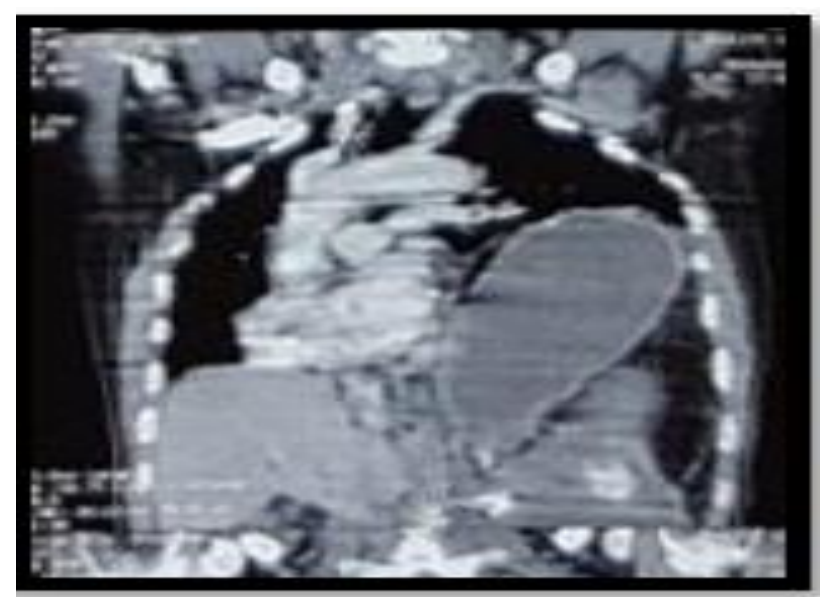

Figure 3: Showing NCCT abdomen and vertical section.

\section{Management}

\section{Operative procedure}

Laparoscopic repair of diaphragmatic hernia with gastropexy. Intra operative findings distended and rotated stomach with colon and spleen lying in left thorax through defect in diaphragm of size $10 \times 15 \mathrm{~cm}$, left diaphragmatic pleura intact, spleenic flexure of transverse colon adherent to the lower end of diaphragm (Figure 4). Procedure done reduction of contents from left chest cavity by gentle pulling, normal saline lavage of peritoneum, ICT to left pleural cavity and suturing of diaphragm by interrupted 1 proline. Jejunal mesenteric laceration, repaired with 3-0 vicryl with tube drain to pelvis. Chest tube removed on $3^{\text {rd }}$ POD and chest X-ray repeated which was normal (Figure 5). Patient was stable, no fresh complaints patient was discharged on POD-5 (Figure 6).

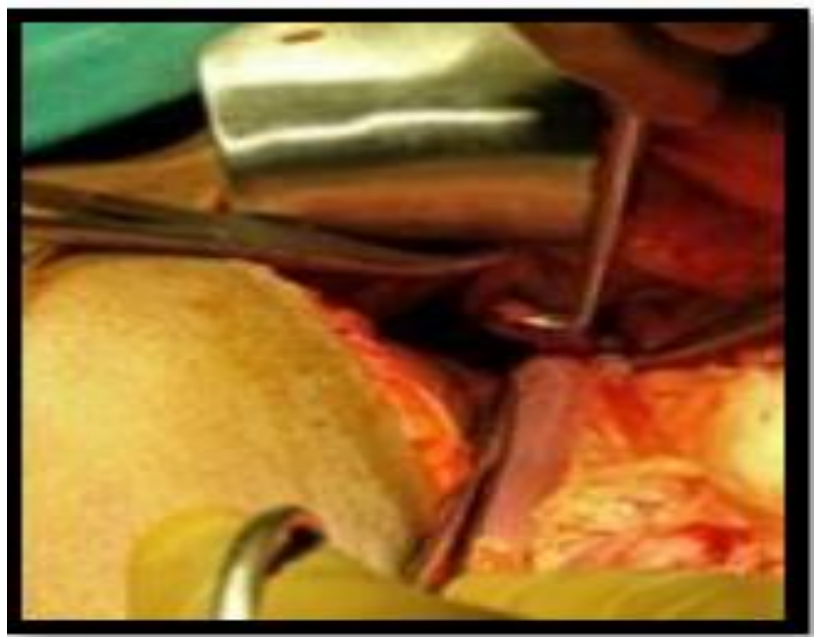

Figure 4: Showing intra-operative picture with bowel in thorax with a large rent in diaphragm.

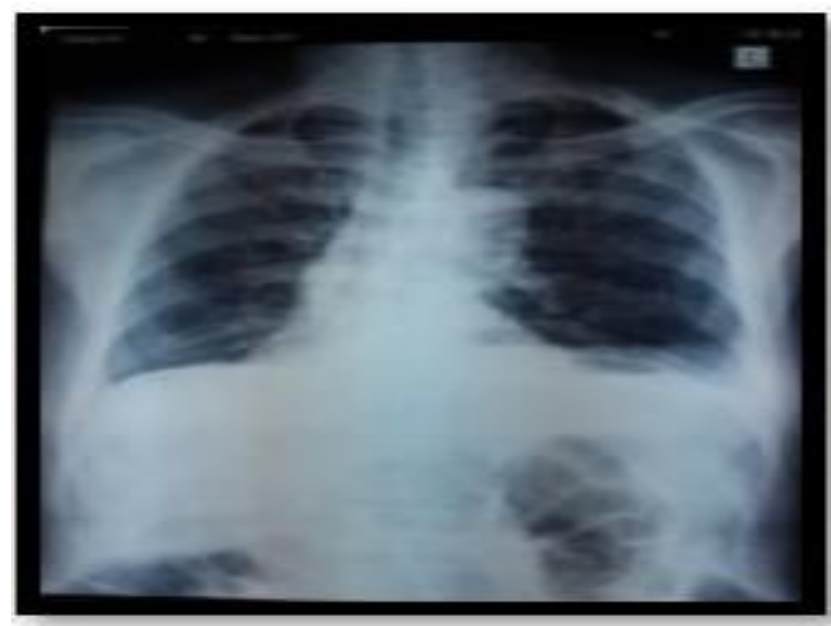

Figure 5: Showing chest X-ray PA view post operatively. 


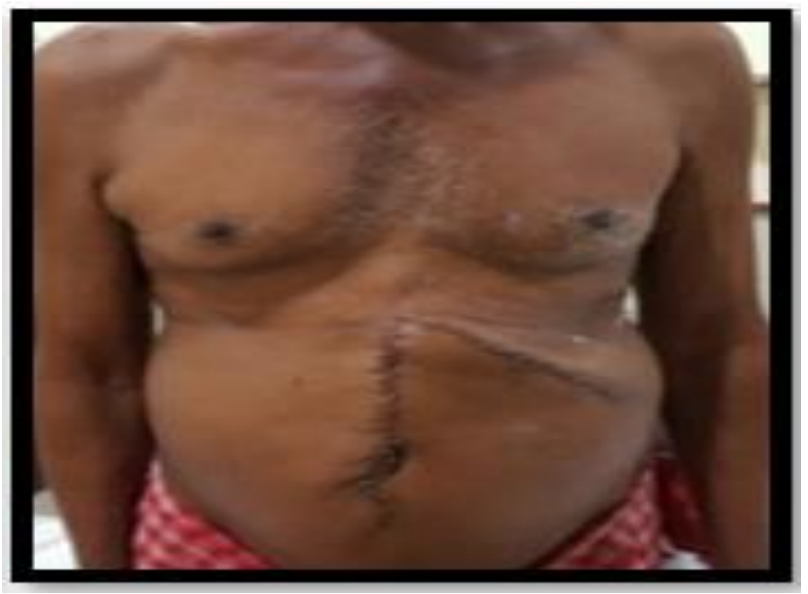

Figure 6: Showing post-operative scar of the patient in POD-5.

\section{DISCUSSION}

Gastric volvulus is a very rare and life-threatening condition where abnormal rotation of the stomach around its axis by more than $180^{\circ}$. Exact incidence unknown, but most of the literatures suggestive of this is marked in either children (with in 1 year) or adults ( $5^{\text {th }}$ decade). Acute cases may be misdiagnosed as a nonsurgical gastrointestinal issue. ${ }^{4}$ The pathophysiology may involve either a laxity or a disruption of ligaments anchoring the stomach. However, in majority of cases, the aetiology is secondary to an underlying condition such as paraesophageal hernia, diaphragmatic herniation or trauma, tumor, or phrenic nerve paralysis. Types chronic most common presentation with dysphagia. Acute rare present with acute pain in epigastrium due to ischemia/gangrene/perforation. It can be also classified as, organoaxial (along longitudinal axis-most common) acute presentation with vascular compromise, diaphragmatic defects, adults). Mesentroaxial (along vertical axis) common in children without features of recurrent abdominal pain, diaphragmatic defects. Combined clinical features Borchardt's triad, others UGI bleed, dysphagia, altered bowel habit, GERD, respiratory symptoms. Complications strangulation, gastric necrosis, perforation, necrosis, GI haemorrhage, cardio-pulmonary failure. Treatment aims reduction of volvulus, gastric fixation, repair of predisposing factor. Approaches open repair of diaphragmatic hernia then epair of eventration of diaphragm, gastropexy, Tanner's procedure, division of bands G-J, partial gastrectomy in case of necrosis. Laparoscopic reduction of volvulus and anchoring fundus of stomach to diaphragm and greater curvature of stomach to anterior abdominal wall, diaphragmatic defects repair, fundoplication. Endoscopic reduction, $\alpha-$ loop maneuver type maneuver, with or without gastrostomy (for fixation of stomach). ${ }^{6,7}$

\section{CONCLUSION}

It's an uncommon life-threatening disease. High suspicion of gastric volvulus due to presence of classic Borchardt's triad should trigger for further investigations. Immediate surgical decision should not be delayed in order avoid complications like gastric necrosis and perforation.

\section{Funding: No funding sources Conflict of interest: None declared Ethical approval: Not required}

\section{REFERENCES}

1. Balas AH, Hani MB, Omari HZ. Radiological features of acute gastric volvulus in adult patients. Clin Imaging. 2010;34:344-7.

2. Rashid F, Thangarajah T, Mulvey D. A review article on gastric volvulus: a challenge to diagnosis and management. Int J Surg. 2010;8:18-24.

3. Cherian P, Khoury J, Albornoz MA. Acute epigastric pain and recurrent vomiting in an elderly man. Postgrad Med J. 1999;75:305-6.

4. Kim HH, Park SJ, Park MI, Moon W. Acute intrathoracic gastric volvulus due to diaphragmatic hernia: a rare emergency easily overlooked. Case Rep Gastroenterol. 2011;5(2):272-7.

5. Altintoprak F, Yalkin O, Dikicier E. A rare etiology of acute abdominal syndrome in adults: gastric volvulusCases series. Int $\mathbf{J}$ Surg Case Rep. 2014;5(10):731-4.

6. Coe TM, Chang DC, Sicklick JK. Small bowel volvulus in the adult populace of the United States: results from a population-based study. Am J Surg. 2015;210(2):201-12.

7. Costa MRP, Matos ASB, Almeida JR, Oliveira FJ. Primary gastric volvulus: a report of two cases. J Surg Case Rep. 2018;2018(8):227.

Cite this article as: Padhy AP, Pranay I, Biradar S. An unusual presentation of acute gastric volvulus in the elderly patient: a case report and literature review. Int Surg J 2020;7:2796-8. 